\title{
The pattern of ambulance arrivals in the emergency department of an acute care hospital in Singapore
}

\author{
E Seow, H P Wong, A Phe
}

\begin{abstract}
Objectives-(1) To determine the pattern of ambulance arrivals in the emergency department (ED) and (2) to review resource allocation based on these data.

Methods-All (13 697) ambulance arrivals in 1996 to the ED of Tan Tock Seng Hospital were studied and where relevant compared with the walk in and total arrivals of the same year. The following data were obtained from computer records: (a) patients' demographic data; (b) number of ambulance arrivals by hour; (c) the classification of the ambulance arrivals by emergency or non-emergency, trauma or non-trauma; (d) cause of injury for trauma cases; (e) discharge status.

Results-The ambulance arrivals in 1996 constituted $12.4 \%$ of the patient load for this department. There was no difference in modes of patient arrival to the ED by sex and ethnic group. However, there was significant evidence to show that more patients age $>\mathbf{6 0}$ came by ambulance than those age $<12(p<<0.01)$. Some $98.5 \%$ of the ambulance arrivals were emergencies; $40.7 \%$ of the ambulance arrivals were attributable to trauma versus $27.3 \%$ of the walk in arrivals. The majority of the trauma cases brought in by ambulance were because of road traffic accidents $(15.3 \%)$ or home accidents $(7.4 \%)$. The peak in ambulance arrivals was between 2100-2300 hours compared with 1000-1200 for the walk in arrivals. More than half of the ambulance arrivals were admitted. Conclusion-In planning resource allocation and in the development of contingency plans, the resource use of ambulance patients and the pattern of their arrivals should be taken into account.
\end{abstract}

(Emerg Med f 2001;18:297-299)

Emergency Medicine, Tan Tock Seng

Hospital, 11 Jalan Tan

Tock Seng, Singapore

308433

E Seow

H P Wong

Office of Quality Management, Tan Tock Seng Hospital

A Phe

Correspondence to: Dr Seow

(eillyne_seow@notes.ttsh. gov.sg)

Accepted for publication 12 June 2000

Keywords: ambulance arrivals; walk in arrivals; emergencies

In Singapore, a patient brought into the emergency department (ED) of an acute care hospital by ambulance generally requires more resources than does the patient who comes by other modes of transport (walk in).

In 1996, the six acute care general hospitals in Singapore attended to 541833 patients of which $9.3 \%$ (50 660) arrived by ambulance. ${ }^{1}$ Of the patients brought by ambulance, the ED of Tan Tock Seng Hospital (TTSH) received 13697 (27\% of the total), the highest among all the hospitals. This is probably because the
Table 1 Patient load and ambulance arrivals in the emergency departments

\begin{tabular}{lcc}
\hline Emergency departments & $\begin{array}{l}\text { Number of } \\
\text { patients }\end{array}$ & $\begin{array}{l}\text { Number of } \\
\text { ambulance } \\
\text { arrivals }\end{array}$ \\
\hline Six acute care hospitals & 541833 & 50660 \\
Hospital A & 171255 & 11914 \\
Tan Tock Seng Hospital & 110584 & 13697 \\
Hospital C & 92377 & 8314 \\
Hospital D & 89210 & 7938 \\
Hospital E & 53911 & 5150 \\
Hospital F & 24496 & 3647 \\
\hline
\end{tabular}

hospital is near two expressways (motorways) and is the only acute hospital located in the central part of the country.

This department was the second largest and attended to $110584(20.4 \%$ of 541833$)$ patients in the study year (table 1 ).

TTSH was in the midst of planning its new building, which included a new ED. As resources and space were limited, it was important to know the pattern of ambulance arrivals for these to be used judiciously. The present ED started operations at its new site in April 1999.

\section{Methods}

This is a retrospective study of all ambulance arrivals in the ED of TTSH from 1 January to the 31 December 1996. The following patient data were obtained from computer records:

(1) sex, age and ethnic group

(2) number of ambulance arrivals by hour of the day

(3) number who were classified as emergency and non-emergency, trauma and nontrauma

(4) number of trauma cases according to the cause of injury

(5) discharge status.

Data of walk in arrivals during the study period were also extracted for comparison.

Results
In this study there were 13697 (12.38\% of total ED attendance) patients brought in by ambulance.

DEMOGRAPHIC PROFILE

The demographic profile of ambulance patients were compared with that of the walk in patients (table 2).

There were no differences in the modes of arrival at the ED by sex and ethnic groups. However, there was evidence to show that majority of patients aged $<12$ years were walk in patients whereas a significant number of patients $>60$ years came by ambulance $(\mathrm{p}<<0.01)$. A finding similar to that made by Rucker et al. ${ }^{2}$ 
Table 2 Profile of ambulance and walk in patients

\begin{tabular}{lcr}
\hline & $\begin{array}{l}\text { Ambulance } \\
\text { patients (\%) }\end{array}$ & \multicolumn{1}{l}{$\begin{array}{l}\text { Walk in patients } \\
(\%)\end{array}$} \\
\hline $\begin{array}{l}\text { By sex } \\
\text { Male }(\mathrm{n}=69 \text { 080) }\end{array}$ & $8380(12.1)$ & $60700(87.9)$ \\
Female ( $\mathrm{n}=41$ 504) & $5317(12.8)$ & $36187(87.2)$ \\
By ethnic group & & \\
Chinese $(\mathrm{n}=72$ 904) & $9382(12.9)$ & $63522(87.1)$ \\
Malay ( $=13$ 149) & $1832(13.9)$ & $11317(86.1)$ \\
Indian $(\mathrm{n}=14$ 933) & $1504(10.1)$ & $13429(89.9)$ \\
Others $(\mathrm{n}=9598)$ & $979(10.2)$ & $8619(89.8)$ \\
By age group & $1208(5.4)$ & $21097(94.6)$ \\
$<12$ years $(\mathrm{n}=22$ 305) & $989(11.1)$ & $7887(88.9)$ \\
13-19 years $(\mathrm{n}=8876)$ & $6377(11.0)$ & $51359(89.0)$ \\
20-59 years $(\mathrm{n}=57$ 736) & $5123(23.6)$ & $16544(76.0)$ \\
$>60$ years $(\mathrm{n}=21667)$ & & \\
\hline
\end{tabular}

Table 3 Number of patients by time intervals

\begin{tabular}{lcl}
\hline $\begin{array}{l}\text { Time intervals } \\
\text { (hours) }\end{array}$ & $\begin{array}{l}\text { Ambulance patients } \\
\text { (\%) }\end{array}$ & Walk in patients (\%) \\
\hline $0000-0759$ & $2575(18.8)$ & $17540(18.1)$ \\
$0800-1559$ & $5363(39.2)$ & $41541(42.9)$ \\
$1600-2359$ & $5753(42.0)$ & $37812(39.0)$ \\
Total & $13691(100)$ & $96893(100)$ \\
\hline
\end{tabular}

TIME OF ARRIVAL

There were two peaks in ambulance arrivals; the higher one (1583 arrivals) was between 2100-2300 hours and the second (1444 arrivals) was between 1000-1200 hours. The peaks in walk in arrivals were similar except that the peak was highest (12 550 arrivals) in the day between 1000-1200 hours and second highest (10 801 arrivals) between $2000-2200$ hours. The number of arrivals was the lowest for both ambulance and walk in between 0000-0759 hours (table 3 ).

\section{EMERGENCY/NON-EMERGENCY,}

TRAUMA/NON-TRAUMA

The majority $(98.5 \%)$ of the ambulance and $91.5 \%$ of the walk in arrivals were classified as emergencies following guidelines given by Ministry of Health, Singapore. ${ }^{3}$

It is interesting to note that the percentage of ambulance patients classified as emergency was similar (between $95.6 \%$ to $98.7 \%$ ) in all the acute hospitals in Singapore except one (Hospital C in table 1), which had $87 \%$.

Some $40.7 \%$ of the ambulance arrivals were attributable to trauma compared with $27.3 \%$ of the walk in cases $(\mathrm{p}<<0.01)$.

CAUSE OF INJURY

The majority of trauma cases brought in by ambulance were attributable to road traffic accidents (2092) or home accidents (1012). The other causes include industrial accidents, assaults and sports.

DISCHARGE STATUS

Those of the ambulance and walk in cases were compared (table 4).

The majority $(53.7 \%)$ of ambulance cases were admitted compared with $29.3 \%$ of the walk in cases $(p<<0.01)$.

A significant proportion (31.8\%) were treated and discharged although this was a smaller proportion compared with that of the walk in arrivals $(\mathrm{p}<<0.01)$.
Table 4 Discharge status of ambulance and walk in cases

\begin{tabular}{lll}
\hline Discharge status & $\begin{array}{l}\text { Ambulance } \\
(n=13 \text { 697 })\end{array}$ & $\begin{array}{l}\text { Walk in } \\
(n=96887)\end{array}$ \\
\hline Admitted & 53.7 & 29.3 \\
Treated and discharged & 31.8 & 43.4 \\
Specialist review & 7.0 & 18.2 \\
Follow up by primary care & & \\
$\quad$ physician & 3.6 & 2.6 \\
Died in the ED & 1.2 & 0.07
\end{tabular}

Data shown as percentages.

\section{DATA COLLECTION}

The computer records of patients' characteristics and number of ambulance arrivals by hour was captured when the patients were registered. These data would have minimum errors.

However, the classification of emergency, non-emergency, trauma, non-trauma, cause of injury and the discharge status is determined by the doctor who attends to the patient and is subject to a certain amount of bias.

As in systems where data are transferred from paper records to a computer database, mistakes in data entry will occur. Supervisors check data entry to minimise errors in this area.

\section{Discussion}

The public emergency ambulance service in Singapore is centralised and provided by the Singapore Civil Defence Force, which also runs the Fire Service. Anyone can activate this service by calling the emergency number 995 . The emergency medical dispatchers cannot refuse to send an emergency ambulance. In 1996, the users of this service did not have to pay. As such, the socioeconomic status of our patients would not have influenced their decisions to call 995 or not. However, since May 1999, users of the emergency ambulance service who are deemed by the emergency physician of the receiving hospital to be non-emergency cases have been charged S\$115 for the service: whether this will deter misuse of our emergency ambulance service remains to be seen. An alternative for the public is to call for an ambulance from one of the private ambulance companies that charge between $\$ 50$ to $\$ 75$ per trip depending on the time of the day. All patients attended to in the emergency department of the six acute care hospital in Singapore pay the same consultation fee (presently \$65) irregardless of their classification as emergency, non-emergency, ambulance or walk in.

Snooks $e t a l^{4}$ in her review found "surprisingly little variation in the range of estimates of inappropriate use" of ambulances. She found the figures for inappropriate use to be between $30 \%$ to $52 \%$ for nine of the 10 studies she reviewed and $11.3 \%$ for the 10 th study. This differed from our figures and was probably because of the different definitions used. The papers reviewed by Snooks et $a l^{4}$ studied ambulance patients from the point of ambulance use while this paper studied them from that of an ED. As such, we were unable to comment on the "misuse of emergency ambulance service" as a patient classified as an emergency, for example, burnt hands, by the ED could have arrived by alternate modes of transportation. ${ }^{6}$ 
In this study, we were not concerned with the "appropriateness of use of emergency ambulances" 5 but rather with the impact ambulance arrivals had on the ED. We used the same criteria in the categorisation of emergency and non-emergency for both ambulance and walk in arrivals. Using this, we found that our figures were not only similar in most of the EDs in Singapore but even with one in Hong Kong. The Accident and Emergency (A\&E) Department, North District Hospital in Hong Kong in 1999 received 18440 ambulance patients; $96 \%$ were classified as emergencies. This A\&E department had a census of 122013 patients (personal correspondence).

Unless the number of ambulance patients an ED receives is small, this group of patients will have a significant impact on it. Our aim in determining the pattern of ambulance arrivals was to review our resource allocation and to find ways to maximise them. The data collected will also serve as baseline information for future audit.

Administrators calculate our manpower requirement based on the number of patient attendances. We now present our manpower requirement based on this as well as the type of patients we see (ambulance or walk in, emergency or non-emergency, triage category) especially ambulance arrivals as we receive a significant number of them.

To optimise manpower deployment, it is prudent to know the arrival patterns of ambulance and walk in patients. For us, our patient load whether they were brought in by ambulance or not peaked at similar times - that is, 1000-1200, 2000-2200 and 2100-2300 hours. The staff shifts were staggered such that the number of staff working during these periods was also at its peak. Meal breaks were also staggered with the minimum number of staff being released during the two peak periods.

As ambulance and non-ambulance arrivals peaked during the same periods and the number of emergency arrivals were similar, it was decided that there should be three entrances to the new ED; one for walk in, the second for ambulance arrivals and a third into the resuscitation room. The walk in entrance lead to the waiting area. There was a separate door into the consultation area for walk in patients from the waiting area. The ambulance entrance opened into a passageway leading directly to the same consultation area through a second door. The separate door into the resuscitation room was especially useful during peak periods as it allowed ambulance crews to bypass the rest of the patients. We had also been able to give relatives of ambulance patients who were brought into the resuscitation room a greater measure of privacy. The separate entrances (walk in and ambulance) gave ambulance crews a relatively free thoroughfare and decreased the risk of walk in patients being hit by trolleys. Overall this had resulted in better crowd control for our ED.

We are planning to deploy clerical staff to do registration within the consultation and resuscitation areas to further shorten the turnaround interval ${ }^{7}$ of our ambulance crews.
The data supported our impression that a significant proportion of patients brought in by ambulance were

(1) more likely to be ill; $98.5 \%$ were deemed emergencies by ED classification

(2) more likely to be admitted

(3) greater than 60 years old.

Because of the above findings, we reviewed our work processes, the number and type of equipment for the new department.

The following changes were made:

(1) Despite space being a premium we set aside ample area for transfer of patients from ambulance to hospital trolleys thus providing a conducive environment for ambulance staff to hand over the care of these patients to ED staff formally.

(2) Stable ambulance patients are triaged by nurses in the consultation area; this is a separate team from the ones triaging the walk in patients.

(3) An increase in the number of patient trolleys.

(4) The establishment of a procedure to borrow patient trolleys from other departments when the ED runs out of trolleys.

(5) Strengthening ties between the ED and the Department of Geriatric Medicine.

An important change that has occurred in our practice has been that of formally triaging our ambulance patients on arrival or as soon as possible as they are generally more ill. When they are actually attended to by a doctor is dependent strictly on the acuity of their condition because of the large number of ambulance cases we receive. Previously, there was a tendency for us to attend to ambulance patients before attending to the walk in patients. This resulted in some walk in patients waiting longer than would have been appropriate.

We suspect that EDs in most parts of the world especially those with similar census have common problems. Patients transported by our ambulance services should not be the concern of our Emergency Medical System only. We have found it useful to study our ambulance arrivals and strongly recommend that EDs do so as an aid in planning their allocation and in the review of their workplans.

We would like to thank Dr Chung Chin Hung for his help in providing the statistics of the Accident and Emergency Department, North District Hospital, Hong Kong.

Funding: none.

Conflicts of interest: none.

1 Summary analysis of work done in public sector hospitals, primary health care and dental clinics. Singapore: Ministry of primary health

2 Rucker DW, Edwards RA, Burstin HR. Patient-specific predictors of ambulance use. Ann Emerg Med 1997;29:484-90

3 Classification, of patients as "Emergency" ("E") and "NonEmergency" ("non-E") at $A \mathcal{E} E$ department. Singapore: Ministry of Health, 7 May 1998.

4 Snooks H, Wrigley H, George S, et al. Appropriateness of use of emergency ambulances. F Accid Emerg Med 1998;15: 212-18

5 Palazzo FF, Warner OJ, Harron M, et al. Misuse of the London ambulance service: how much and why? F Accid Emerg Med 1998;15:368-70.

6 Billittier AJ, Moscati R, Janicke D, et al. A mulitsite survey of factors contributing to medically unnecessary ambulance factors contributing to medically unnecessary
transports. Acad Emerg Med 1996;3:1046-52.

7 Cone DC, Davidson SJ, Nguyen Q. A time-motion study of the emergency medical services turnaround interval. Ann Emerg Med 1998;31:241-6. 